\title{
Epileptic Encephalopathies in Adults and Childhood
}

\author{
Zekiye Kural $^{1}$ and Ali Fahir Ozer ${ }^{2}$ \\ ${ }^{1}$ Neurology Department, American Hospital, 34365 Istanbul, Turkey \\ ${ }^{2}$ Neurosurgery Department, Koc University School of Medicine, Rumelifeneri Yolu Sarryer, Istanbul 34450, Turkey
}

Correspondence should be addressed to Ali Fahir Ozer, alifahirozer@gmail.com

Received 13 January 2012; Revised 28 March 2012; Accepted 10 June 2012

Academic Editor: Nicola Specchio

Copyright (C) 2012 Z. Kural and A. F. Ozer. This is an open access article distributed under the Creative Commons Attribution License, which permits unrestricted use, distribution, and reproduction in any medium, provided the original work is properly cited.

Epileptic encephalopathies are motor-mental retardations or cognitive disorders secondary to epileptic seizures or epileptiform activities. Encephalopaties due to brain damage, medications, or systemic diseases are generally not in the scope of this definition, but they may rarely accompany the condition. Appropriate differential diagnosis of epileptic seizures as well as subclinical electroencephalographic discharges are crucial for management of seizures and epileptiform discharges and relative regression of cognitive deterioration in long-term followup. Proper antiepileptic drug, hormonal treatment, or i.v. immunoglobulin choice play major role in prognosis. In this paper, we evaluated the current treatment approaches by reviewing clinical electrophysiological characteristics of epileptic encephalopathies.

\section{Introduction}

Epileptic encephalopathy is described as epilepsy with ictal and interictal epileptiform anomalies (clinical and EEG) and progressive cerebral dysfunction according to the classification and terminology criteria of International League against Epilepsy (ILAE) [1-3]. The following are syndromes meeting the criteria: Dravet syndrome, Doose syndrome, ESES (electrical status epilepticus of slow sleep) or CSWSS (continuous spike waves of slow sleep), Landau-Kleffner syndrome, Lennox-Gastaut syndrome, Ohtahara syndrome, and West syndrome [4]. Severe epilepsy with multiple independent spike foci is recently included in this group $[2,4]$.

Steroid-sensitive epileptic encephalopathies such as Hashimoto encephalopathy, progressive myoclonus epilepsies, and neonatal epileptic encephalopathies are not classified in this group but are worth mentioning [5-10].

\section{Dravet Syndrome or Severe Myoclonic Epilepsy of Infancy}

An important group of epileptic encephalopathies that are resistant to treatment, a severe myoclonic epilepsy of childhood, first described by Dravet in 1978, is characterized with recurrent febrile and/or afebrile, hemiclonic or generalized seizures, and status epilepticus. Child's development stops or retards after the onset of seizures [11-14]. Prevalence is unknown. The incidence is $0.5-1 / 40.000$ and develops in $3-5 \%$ and $6.1-8.2 \%$ of all epilepsies in the first year and within the 3 years of life, respectively. Male-female ratio is $2: 1$. The most common cause is SCN1A mutations or deletions $(35 \%)$ [11, 15-17]. Consequences in patients who reached adulthood and were observed for long term as well as neuropathology of the disease are unknown.

Patients with family history of febrile convulsion or epilepsy are reported to consist $25-71 \%$ in various patient series. Incidence is also significant in identical twins. GEFS is $(+)$ in most of the cases. Ten percent of the cases are asymptomatic and SCN1A mutation is reported in their mildly affected family members. The possible genes involved are shown to be SCN1B, GABRG2, PCDH19, SCN2A, and 2q SCN $[12,18-26]$. On the other hand, the association of SCN9A with febrile convulsions and Dravet's syndrome is also emphasized [27].

Common characteristics of Dravet's syndrome in animal models and patient groups are increased interictal epileptiform discharges or epileptic seizures due to sensitivity to increased body temperature and increased seizure frequency and severity due to aging $[12,13,26,28]$. The abovementioned characteristics refer to juvenile form of Dravet's 
syndrome and are based on solid evidence from several studies. Sufficient data about the adult form is not available $[12,29]$. MRI findings are normal in most of the cases. Adult form of Dravet's syndrome may present with cerebralcerebellar atrophy or cerebellar atrophy only [29].

Between ages of 1-5, myoclonic seizures may manifest with massive, generalized myoclonic jerks, and sudden falling attacks. Myoclonic jerks increase throughout the day and with emotional lability and disappear in sleep. Focal seizures may develop in $45-80 \%$ of the cases between 4 months and 4 years in simple partial motor or complex partial form, persisting as unilateral seizure or may develop into generalized seizure $[11,15,30]$.

EEG is generally normal within the first 12 months. Generalized spike, spike and wave (5-6 sec) complexes may be observed in multiple foci localized in central regions and vertex photosensitivity is reported in 50\% of the cases. Unexpected EEG findings have recently been reported [11, 28, 30].

Treatment is resistant to several medications. Carbamazepine and lamotrigine are shown to exacerbate the seizures. Effects of other anticonvulsants vary. VAP, TPM, and LEV are the most promising agents used in USA. In Europe, more successful results are achieved by combining stiripentol, a cytochrome P450 inhibitor, with clobazam (CLB) and VPA, especially in prevention of status epilepticus $[12,31]$. Recent studies indicate that addition of a voltagegated calcium channel blocker, such as verapamil, to anticonvulsant therapy is beneficial. Ketogenic diet is another method for management or minimizing seizure frequency [31-37].

\section{Myoclonic-Astatic Epilepsy or Doose Syndrome}

Myoclonic-astatic epilepsy or Doose syndrome is a form of generalized epilepsy developing between 7 months and 6 years of life with myoclonic attacks, absence and tonic seizures $[1,38,39]$. Peak age is $1-5$ and males are more prone than females. One-third of cases have history of febrile convulsion [1, 15]. EEG may show spike-wave, wave-multiple spike complexes in ictal period with 2$4 \mathrm{~Hz}$ frequency. It is initially normal in interictal period, $3 \mathrm{~Hz}$ wave-spike discharges may be observed in sleep in later periods [40-42]. Fifty-eight percent of the cases have normal intelligence, while $20 \%$ and $22 \%$ show mild and severe mental retardation, respectively. Cases with mental deterioration are usually resistant to treatment. Seizures may be managed after 3 years in a certain percentage of patients $[22,42,43]$. Neuroradiological findings are generally normal [41]. Genetical basis is not clear [22, 38, 39]. VPA and ethosuximide (ESM) are still the commonly preferred medications for management of myoclonic seizures [40, 42]. Although BDZ and clonazepam (CZP) are beneficial for management of generalized seizures, they are not preferred since they cause behavior changes [41]. Lamotrigine (LTG) can be used for generalized seizures [44, 45]. CBZ and vigabatrin $(\mathrm{GVB})$ are not recommended [41].
Topiramate (TPM), levetiracetam (LEV), acetazolamide (AZD) and sulthiame (SLT) are common; however, the number of cases and studies is not sufficient [22, 41, 4648]. Ketogenic diets are effective but difficult to maintain for long periods [40, 49]. Progressive myoclonic epilepsies, that is, MERRF syndrome (myoclonus epilepsy with raggedred fibers) can be mistaken for with Unverricht-Lundborg disease, and late-infantile neuronal ceroid lipofuscinosis; however, neurological development in later stage, continuity and persistence of the disease facilitate differential diagnosis.

\section{ESES or CSWSS}

First defined in 1971 as a juvenile form of epileptic syndrome named subclinical status epilepticus, ESES (or CSWS) is characterized with neuropsychologic and behaviour changes and develops during sleep [3, 10, 50]. ESES and CSWS are synonyms; however, ESES indicates EEG findings while CSWS refers to electroclinical findings $[10,51]$. Prevalence is not known, but incidence is reported to be $0.5 \%$. Equal male-female incidence is defined in early studies; extended studies indicate higher incidence in males. Generalized tonic-clonic seizures, atypical absence, myoclonic and atonic seizures may be observed. Mental retardation, lower IQ secondary to deterioration, and motor loss such as aphasia, behaviour disorder, ataxia, and dyspraxia accompany the seizures. Clinical course is composed of 3 stages: (1) initial period with seizures and no mental retardation; (2) intermediate period composed of neuropsychologic regression, seizures and ESES, and (3) final period composed solely of neuropsychological deficit. Cases solely presenting with mental retardation or behaviour disorder with no seizures are also noted [10,52-56]. In these cases, diagnosis is confirmed with night video-polysomnography (V-NPSG). In most cases, EEG anomalies and neuropsychologic losses continue in puberty meanwhile there may be regression in seizures, improvement in behaviour and motor findings, and normal EEG pattern may return. Although genetic factors are unknown, a study reported relation with familial seizures and monozygotic state, and $15 \%$ of cases is associated with febrile convulsions [56, 57]. MRI and CT studies indicated $33 \%$ anomaly with significant diffuse or unilateral cerebral atrophy [58]. LTG, LEV, VPA, steroids, and BDZ are among treatments, the best outcomes are observed with diazepam (DZP) $[6,59]$. Corticosteroids are beneficial in some resistant cases [60-62].

\section{Landau-Kleffner Syndrome}

William Landau and Frank Kleffner reported epileptic encephalopathy for the first time in 1957 in six children who underwent various types of seizures and developed acquired aphasia $[6,63]$. LKS first appears between ages of 3 and 7 in children with normal motor-mental-linguistic development [64]. Range may be $2-14$ in rare cases. Male-female ratio is $2: 1$. Family history is incidentally $(+)$. The main criterion is determined as normal development in premorbid period; however, preexisting language anomaly is reported in $13 \%$ of 
the cases. Aphasia is progressive and usually develops gradually. Total speech loss develops approximately in 1 year and acute-onset aphasia is rare. Various types of aphasia may be observed during the whole course. Hearing is usually normal, but patients may develop mutism and unresponsiveness to all verbal and nonverbal stimuli. Hyperactivity, aggressiveness, impulsiveness and attention deficit are extremely common [65-69]. EEG shows spikes or spike-waves prominent in temporal or centrotemporal sleep. Methohexital suppression test, intraoperative electrocorticography, and magnetoencephalography results are localized in superior temporal gyrus, intra- and peri-Sylvian cortex. EEG is rarely normal in sleep. ESES can be observed rarely. In pathogenesis, frequent EEG discharges are estimated to interrupt central pathways of speech development. This relation is explained for similar syndromes like Benign childhood epilepsy with centrotemporal spikes (BECTS) [59, 70-74]. MRI findings are normal. SPECT studies reveal temporal hypo- or hypermetabolism. Hypermetabolism are associated with active epileptic discharges [68].

LKS prognosis is poor depending on the earlier date of onset (prelinguistic). However, some cases show significant improvement in communication in second and third decades of life [75]. Seizure management is usually successful with appropriate drug choice. CBZ may deteriorate the seizures, monotherapy with VPA or its combination with BDZ seem to be the best choice. Higher and long-term use of adrenocorticotropic hormone (ACTH) and steroids is strongly recommended due to beneficial results. CLB, nitrazepam (NZP), VPA, ESM, and flunitrazepam are used, and PB, CBZ, and PHT are not used. IV immunoglobulins are as successful as steroids [60-62, 74-76].

\section{Lennox-Gastaut Syndrome}

LGS is a rare form of epileptic encephalopathy, first described in 1969 by Lennox and Gastaut [77]. Classical triad includes early onset with multiple and various types of seizures, mental deterioration, and generalized slow spikes waves in EEG [76-79]. First seizure occurs at $1-8$ years, peaking between 3 and 4, and is etiologically divided into symptomatic and cryptogenic. Major division includes cryptogenic cases. Symptomatic cases are secondary to hypoxicischemic encephalopathy, vascular damage, tuberous sclerosis, Down's syndrome, trauma, brain tumor, and perinatal meningoencephalitis. WS is reported in history of $10-25 \%$ of the cases [44, 80-82] (Figure 1).

Tonic seizures are the most common seizures of LGS (7490\%) and occurrence in the initial period is not mandatory for diagnosis. The second most frequent symptom is atypical absences, followed by atonic seizures and myoclonic seizures. Nonconvulsive status epilepticus is observed in 54-97\% of the cases [81, 82]. EEG findings are characteristic: generalized slow spike-waves $(2-2.5 \mathrm{c} / \mathrm{s})$ and burst in awake state, burst or fast wave and slow polyspikes and generalized fast activity at about $10 \mathrm{c} / \mathrm{s}$ during sleep [80].

Antiepileptic drugs, ketogenic diet, hormonal therapies, and surgical and rehabilitation methods are used in

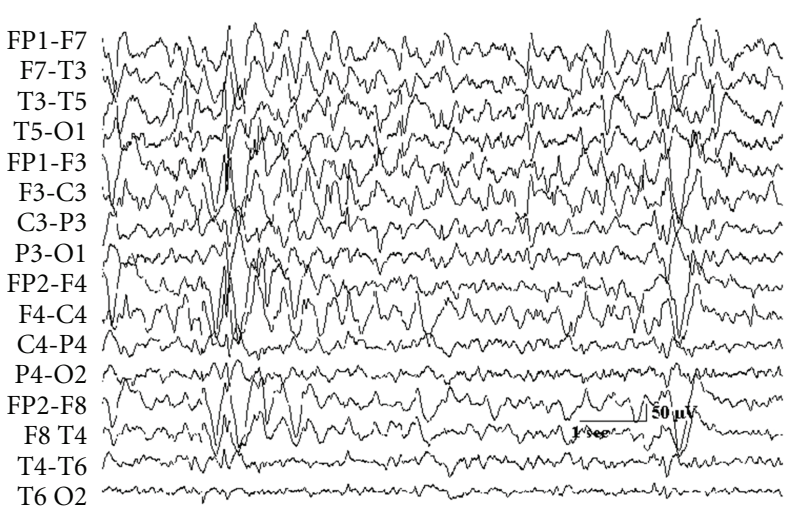

FIGURE 1: Slow electroencephalographic spike and wave discharges in Lennox-Gastaut syndrome.

treatment. Monotherapy or combined therapy with oldgeneration antiepileptic medications did not give significant benefit; however, benzodiazepines are still utilized. The most promising choices seem to be LTG and rufinamide (RUF). Carisbamate (CBM), fluorofelbamate (FFBM), ganaxolone (GNX), and remacemide (RMC) are among the antiepileptic medications of the future. Ketogenic diet is as effective as in all types of intractable epilepsies. Difficulty in continuation and complications of some medications (kidney stones) are of concern. Initiation of ACTH and corticosteroids short time after disease onset, especially in cryptogenic cases, is known to be effective, but they are not used frequently due to increased rate of relapse. Other choices are amantadine, imipramine, IV immunoglobulin, and TRH analogs. Surgical treatment options include callosotomy and VNS (vagal nerve stimulation). Nonmedical treatment methods are composed of specific education and rehabilitation $[45$, 83-90] (Figure 2).

Prognosis is extremely poor. Most of the cases continue to live dependently [80].

\section{Ohtahara Syndrome or Early-Infantile Epileptic Encephalopathy}

Ohtahara Syndrome, first described in 1976 by Ohtahara et al., characterized with tonic seizures and burst suppression pattern in EEG, develops earlier than other forms of epileptic encephalopathies, is resistant to treatment, and has one of the poorest prognosis among other types [6, 91-93]. Cause is unknown but it generally accompanied structural brain anomalies such as Aicardi syndrome, migrational disorders, porencephaly, and hemimegalencephaly; malefemale prevalence is equal. First seizure may occur in the first day of life, but general onset is within 1-3 months [7, 94$101]$.

Single or clusters of tonic spasms occur in awake state or during sleep. Other seizure types are rare. It accounts for $0.2-4 \%$ of all juvenile epilepsies. Seventy-five percent of cases turn into West Syndrome within 3 to 6 months, and some of these turn into Lennox-Gastaut syndrome. 


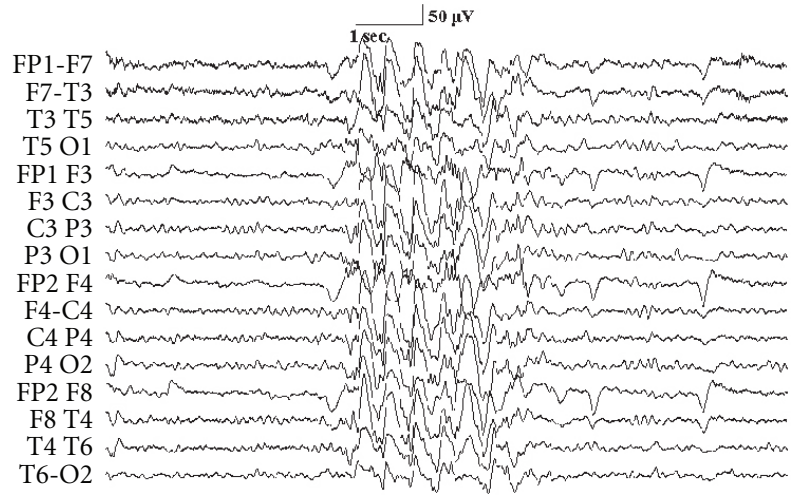

Figure 2: Polyspike and wave discharged been recorded in atypical absence seizures (Lennox-Gastaut syndrome).

ARX gene mutation, Stxbp 1 (MUNC 18-1) mutations are reported in some cases [102-104].

ACTH, VGB, and zonisamide offer some benefits; however, no treatment showed significant improvement in longterm. Severe morbidity and high mortality are inevitable [105-112].

\section{West Syndrome or Infantile Spasms or Salaam Spasms/Tics}

West Syndrome, a well-known form of epileptic encephalopathy first described in 1841 by James West, has a 0.16-0.42 incidence in thousand births [6]. Triad includes epileptic seizures, hypsarrhythmia in EEG and psychomotor retardation [113]. It usually starts within the first year of life peaking at 5 months. Seizures appear in various types and are usually in the form of sudden, bilateral, and symmetrical flexor, extensor or mixed-type spasms of the neck, body, and extremities. These spasms usually have 20-100 clusters [64, 114-117].

Early diagnosis and treatment prevent poorer prognosis and development of Lennox-Gastaut syndrome. There are three forms: symptomatic, idiopathic, and cryptogenic [118] (Figure 3).

EEG shows random high-amplitude slow wave and spike complexes and is first described by Gastaut in 1950, and named hypsarrhythmia by Gibbs. It may gain multifocal character in time or may rarely turn into generalized spike discharges [112-116] (Figure 4).

Preferred agents are ACTH and VGB [115-130].

\section{Severe Epilepsy with Multiple Independent Spike Foci (SE-MISF)}

Ohtahara et al. described the clinical symptoms, also previously described by Noriega-Sanchez and Markand, characterized by high-frequency seizures and MISF in EEG, which generally involves both hemispheres and develops secondary to cerebral pathologies in children between 4-7 years $[41,101]$.

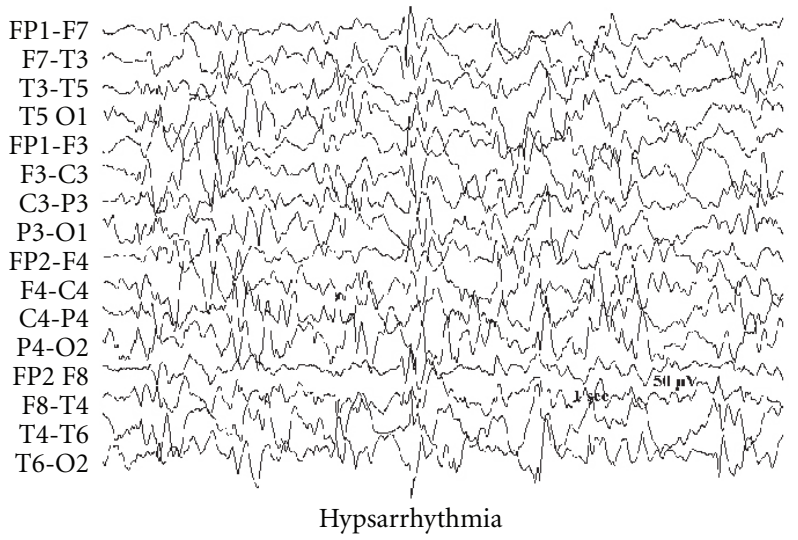

FIGURE 3: Hypsarrhythmia electroencephalogram in infantile spasms shows chaotic high-amplitude background (West syndrome).

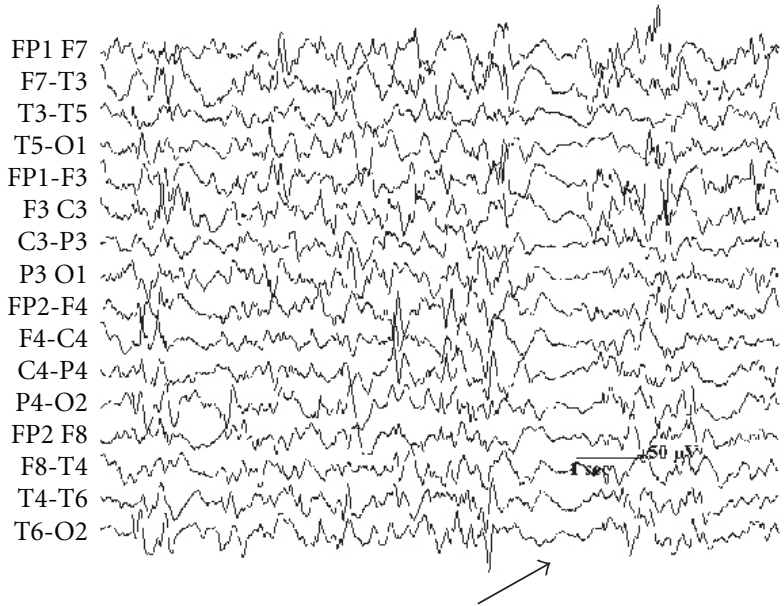

Electrodecremental response in hypsarrhythmia

FIGURE 4: Electroencephalogram response in hypsarrhythmia was associated and recorded in infantile spasms (West syndrome).

Various types of frequent generalized minor seizures usually manifest along with mental retardation. Condition develops secondary to pre-, peri-, and post-natal factors (degenerative disorders, neurocutaneous diseases, infections, hypoxic-ischemic encephalopathy, hydrocephaly, and cerebral malformations), and patients develop WS and LGS, continuing their lives with severe seizures and mental retardation [59, 131-133].

VPA, BDZ, VGB, PTH, and ZNS combinations are used for treatment. Neurosurgical intervention is not an option $[59,133,134]$.

\section{References}

[1] J. Engel, "A proposed diagnostic scheme for people with epileptic seizures and with epilepsy: report of the ILAE task force on classification and terminology," Epilepsia, vol. 42, no. 6, pp. 796-803, 2001. 
[2] Y. Yamatogi and S. Ohtahara, "Early-infantile epileptic encephalopathy with suppression-bursts, Ohtahara syndrome; its overview referring to our 16 cases," Brain and Development, vol. 24, no. 1, pp. 13-23, 2002.

[3] Commission on Classification and Terminology of the International League Against Epilepsy, "Proposal for revised classification of epilepsies and epileptic syndromes," Epilepsia, vol. 30, pp. 389-399, 1989.

[4] P. Parisi, A. Spalice, F. Nicita et al., "'Epileptic encephalopathy' of infancy and childhood: electro-clinical pictures and recent understandings," Current Neuropharmacology, vol. 8, no. 4, pp. 409-421, 2010.

[5] T. P. Nguyen and L. M. El-Hakam, "Clinical reasoning: a 9year-old girl with seizures and encephalopathy," Neurology, vol. 74, no. 22, pp. e97-e100, 2010.

[6] O. Dulac, "Epileptic encephalopathy," Epilepsia, vol. 42, supplement s3, pp. 23-26, 2001.

[7] C. P. Panayiotopoulos, "Epileptic encephalopathy in infancy and early childhood," in A Clinical Guide to Epileptic Syndromes and Their Treatment, C. P. Panayiotopoulos, Ed., pp. 223-273, London, UK, 2nd edition, 2007.

[8] R. Nabbout and O. Dulac, "Epileptic encephalopathies: a brief overview," Journal of Clinical Neurophysiology, vol. 20, no. 6, pp. 393-397, 2003.

[9] E. Oka, S. Ishida, Y. Ohtsuka, and S. Ohtahara, "Neuroepidemiological study of childhood epilepsy by application of international classification of epilepsies and epileptic syndromes (ILAE, 1989)," Epilepsia, vol. 36, no. 7, pp. 658661, 1995.

[10] W. S. MacAllister and S. G. Schaffer, "Neuropsychological deficits in childhood epilepsy syndromes," Neuropsychology Review, vol. 17, no. 4, pp. 427-444, 2007.

[11] M. Wolff, C. Cassé-Perrot, and C. Dravet, "Severe myoclonic epilepsy of infants (Dravet syndrome): natural history and neuropsychological findings," Epilepsia, vol. 47, no. 2, pp. 4548, 2006.

[12] C. Dravet, M. Bureau, H. Oguni et al., "Severe myoclonic epilepsy in infancy (Dravet syndrome)," in Epileptic Syndromes in Infancy, Childhood and Adolescence, J. Roger, M. Bureau, C. Dravet et al., Eds., pp. 89-113, John Libbey, London, UK, 3rd edition, 2002.

[13] C. B. Catarino, J. Y. Liu, I. Liagkouras et al., "Dravet syndrome as epileptic encephalopathy: evidence from longterm course and neuropathology," Brain, vol. 134, pp. 29823010, 2011.

[14] F. E. Jansen, L. G. Sadleir, L. A. Harkin et al., "Severe myoclonic epilepsy of infancy (Dravet syndrome): recognition and diagnosis in adults," Neurology, vol. 67, no. 12, pp. 2224-2226, 2006.

[15] I. E. Scheffer, L. A. Harkin, L. M. Dibbens, J. C. Mulley, and S. F. Berkovic, "Neonatal epilepsy syndromes and generalized epilepsy with febrile seizures plus (GEFS+)," Epilepsia, vol. 46, supplement s10, pp. 41-47, 2005.

[16] G. Fukuma, H. Oguni, Y. Shirasaka et al., "Mutations of neuronal voltage-gated $\mathrm{Na}+$ channel $\alpha 1$ subunit Gene SCN1A in core severe myoclonic epilepsy in infancy (SMEI) and in borderline SMEI (SMEB)," Epilepsia, vol. 45, no. 2, pp. 140-148, 2004.

[17] I. E. Scheffer, Y. H. Zhang, F. E. Jansen, and L. Dibbens, "Dravet syndrome or genetic (generalized) epilepsy with febrile seizures plus?” Brain and Development, vol. 31, no. 5, pp. 394-400, 2009.

[18] C. Depienne, D. Bouteiller, B. Keren et al., "Sporadic infantile epileptic encephalopathy caused by mutations in PCDH19 resembles dravet syndrome but mainly affects females," PLoS Genetics, vol. 5, no. 2, Article ID e1000381, 2009.

[19] C. Dravet, "The Lennox-Gastaut syndrome: from baby to adolescence," in Childhood Epilepsies and Brain Developtment, A. Nehlig, J. Motte, S. L. Moshe et al., Eds., pp. 103112, John Libbey, London, UK, 1999.

[20] L. Claes, B. Ceulemans, D. Audenaert et al., "De novo SCN1A mutations are a major cause of severe myoclonic epilepsy of infancy," Human Mutation, vol. 21, no. 6, pp. 615-621, 2003.

[21] E. Gennaro, P. Veggiotti, M. Malacarne et al., "Familial severe myoclonic epilepsy of infancy: truncation of Nav1.1 and genetic heterogeneity," Epileptic Disorders, vol. 5, no. 1, pp. 21-25, 2003.

[22] R. Nabbout, E. Gennaro, B. Dalla Bernardina et al., "Spectrum of SCN1A mutations in severe myoclonic epilepsy of infancy," Neurology, vol. 60, no. 12, pp. 1961-1967, 2003.

[23] T. Sugawara, E. Mazaki-Miyazaki, K. Fukushima et al., "Frequent mutations of SCN1A in severe myoclonic epilepsy in infancy," Neurology, vol. 58, no. 7, pp. 1122-1124, 2002.

[24] R. H. Wallace, B. L. Hodgson, B. E. Grinton et al., "Sodium channel $\alpha 1$-subunit mutations in severe myoclonic epilepsy of infancy and infantile spasms," Neurology, vol. 61, no. 6, pp. 765-769, 2003.

[25] S. E. Heron, I. E. Scheffer, X. Iona et al., "De novo SCN1A mutations in Dravet syndrome and related epileptic encephalopathies are largely of paternal origin," Journal of Medical Genetics, vol. 47, no. 2, pp. 137-141, 2010.

[26] B. Kassaï, C. Chiron, S. Augier et al., "Severe myoclonic epilepsy in infancy: a systematic review and a meta-analysis of individual patient data," Epilepsia, vol. 49, no. 2, pp. 343348, 2008.

[27] N. A. Singh, C. Pappas, E. J. Dahle et al., "A role of SCN9A in human epilepsies, as a cause of febrile seizures and as a potential modifier of Dravet syndrome," PLoS Genetics, vol. 5, no. 9, Article ID e1000649, 2009.

[28] R. Nabbout, I. Desguerre, S. Sabbagh et al., "An unexpected EEG course in Dravet syndrome," Epilepsy Research, vol. 81, no. 1, pp. 90-95, 2008.

[29] P. Striano, M. M. Mancardi, R. Biancheri et al., "Brain MRI findings in severe myoclonic epilepsy in infancy and genotype-phenotype correlations," Epilepsia, vol. 48, no. 6, pp. 1092-1096, 2007.

[30] R. H. Caraballo and N. Fejerman, "Dravet syndrome: a study of 53 patients," Epilepsy Research, vol. 70, supplement, pp. S231-S238, 2006.

[31] C. Korff, L. Laux, K. Kelley, J. Goldstein, S. Koh, and D. Nordli, "Dravet syndrome (severe myoclonic epilepsy in infancy): a retrospective study of 16 patients," Journal of Child Neurology, vol. 22, no. 2, pp. 185-194, 2007.

[32] G. Coppola, G. Capovilla, A. Montagnini et al., "Topiramate as add-on drug in severe myoclonic epilepsy in infancy: an Italian multicenter open trial," Epilepsy Research, vol. 49, no. 1, pp. 45-48, 2002.

[33] P. Striano, A. Coppola, M. Pezzella et al., "An open-label trial of levetiracetam in severe myoclonic epilepsy of infancy," Neurology, vol. 69, no. 3, pp. 250-254, 2007.

[34] C. Chiron, "Stiripentol," Neurotherapeutics, vol. 4, no. 1, pp. 123-125, 2007.

[35] C. Chiron, M. C. Marchand, A. Tran et al., "Stiripentol in severe myoclonic epilepsy in infancy: a randomised placebocontrolled syndrome-dedicated trial," The Lancet, vol. 356, no. 9242, pp. 1638-1642, 2000. 
[36] B. Ceulemans, M. Boel, L. Claes et al., "Severe myoclonic epilepsy in infancy: toward an optimal treatment," Journal of Child Neurology, vol. 19, no. 7, pp. 516-521, 2004.

[37] P. Iannetti, P. Parisi, A. Spalice, M. Ruggieri, and F. Zara, "Addition of verapamil in the treatment of severe myoclonic epilepsy in infancy," Epilepsy Research, vol. 85, no. 1, pp. 8995, 2009.

[38] H. Doose, "Myoclonic astatic epilepsy of early childhood," in Epileptic Syndromes in Infancy, Childhood and Adolescence, J. Roger, M. Bureau, C. Dravet et al., Eds., pp. 103-114, John Libbey, London, UK, 2nd edition, 1992.

[39] H. Doose and W. K. Baier, "Genetic factors in epilepsies with primary generalized minor seizures," Neuropediatrics, vol. 18, supplement 1, pp. 1-64, 1997.

[40] H. Oguni, T. Tanaka, K. Hayashi et al., "Treatment and long-term prognosis of myoclonic-astatic epilepsy of early childhood," Neuropediatrics, vol. 33, no. 3, pp. 122-132, 2002.

[41] R. Guerrini and J. Aicardi, "Epileptic encephalopathies with myoclonic seizures in infants and children (severe myoclonic epilepsy and myoclonic-astatic epilepsy)," Journal of Clinical Neurophysiology, vol. 20, no. 6, pp. 449-461, 2003.

[42] S. Kilaru and A. G. C. Bergqvist, "Current treatment of myoclonic astatic epilepsy: clinical experience at the Children's Hospital of Philadelphia," Epilepsia, vol. 48, no. 9, pp. 1703-1707, 2007.

[43] M. Filippini, A. Boni, G. Dazzani, A. Guerra, and G. Gobbi, "Neuropsychological findings: myoclonic astatic epilepsy (MAE) and Lennox-Gastaut syndrome (LGS)," Epilepsia, vol. 47, no. 2, pp. 56-59, 2006.

[44] J. J. Chevrie and J. Aicardi, "Childhood epileptic encephalopathy with slow spike-wave. A statistical study of 80 cases," Epilepsia, vol. 13, supplement s2, pp. 259-271, 1972.

[45] K. Van Rijckevorsel, "Treatment of Lennox-Gastaut syndrome: overview and recent findings," Neuropsychiatric Disease and Treatment, vol. 4, no. 6, pp. 1001-1019, 2008.

[46] Y. Mikaeloff, A. de Saint-Martin, J. Mancini et al., "Topiramate: efficacy and tolerability in children according to epilepsy syndromes," Epilepsy Research, vol. 53, no. 3, pp. 225-232, 2003.

[47] M. B. Tennison, R. S. Greenwood, and M. V. Miles, "Methsuximide for intractable childhood seizures," Pediatrics, vol. 87, no. 2, pp. 186-189, 1991.

[48] Y. P. Lin, K. Itomi, H. Takada et al., "Benign myoclonic epilepsy in infants: video-EEG features and long-term follow-up," Neuropediatrics, vol. 29, no. 5, pp. 268-271, 1998.

[49] R. H. Caraballo, R. O. Cersósimo, D. Sakr, A. Cresta, N. Escobal, and N. Fejerman, "Ketogenic diet in patients with myoclonic-astatic epilepsy," Epileptic Disorders, vol. 8, no. 2, pp. 151-155, 2006.

[50] C. A. Tassinari, O. Daniele, and F. Gambarelli, "Excessive 714 sec positive spikes during REM sleep in monozygotic non epileptic twins with speech retardation," Revue d'E.E.G. et de Neuro-Physiologie Clinique, vol. 7, no. 2, pp. 192-193, 1977.

[51] A. S. Galanopoulou, A. Bojko, F. Lado, and S. L. Moshé, "The spectrum of neuropsychiatric abnormalities associated with electrical status epilepticus in sleep," Brain and Development, vol. 22, no. 5, pp. 279-295, 2000.

[52] G. L. Holmes and P. P. Lenck-Santini, "Role of interictal epileptiform abnormalities in cognitive impairment," Epilepsy and Behavior, vol. 8, no. 3, pp. 504-515, 2006.

[53] J. Aicardi and J. J. Chevrie, "Atypical benign partial epilepsy of childhood," Developmental Medicine and Child Neurology, vol. 24, no. 3, pp. 281-292, 1982.
[54] N. Fejerman, R. Caraballo, and S. N. Tenembaum, "Atypical evolutions of benign localization-related epilepsies in children: are they predictable?" Epilepsia, vol. 41, no. 4, pp. 380390, 2000.

[55] R. Guerrini, "Epilepsy in children," The Lancet, vol. 367, no. 9509, pp. 499-524, 2006.

[56] N. Laporte, G. Sébire, Y. Gillerot, R. Guerrini, and S. Ghariani, "Cognitive epilepsy: ADHD related to focal EEG discharges," Pediatric Neurology, vol. 27, no. 4, pp. 307-311, 2002.

[57] C. D. Binnie, D. G. A. Kasteleijn-Nolst Trenite, A. M. Smit, and A. J. Wilkins, "Interactions of epileptiform EEG discharges and cognition," Epilepsy Research, vol. 1, no. 4, pp. 239-245, 1987.

[58] R. Guerrini, P. Genton, M. Bureau et al., "Multilobar polymicrogyria, intractable drop attack seizures, and sleep- related electrical status epilepticus," Neurology, vol. 51, no. 2, pp. 504-512, 1998.

[59] Y. Yamatogi and S. Ohtahara, "Multiple independent spike foci and epilepsy, with special reference to a new epileptic syndrome of 'severe epilepsy with multiple independent spike foci”, Epilepsy Research, vol. 70, pp. S96-S104, 2006.

[60] P. Lerman, T. Lerman-Sagie, and S. Kivity, "Effect of early corticosteroid therapy for Landau-Kleffner syndrome," Developmental Medicine and Child Neurology, vol. 33, no. 3, pp. 257-260, 1991.

[61] W. F. M. Arts, F. K. Aarsen, M. Scheltens-de Boer, and C. E. Catsman-Berrevoets, "Landau-Kleffner syndrome and CSWS syndrome: treatment with intravenous immunoglobulins," Epilepsia, vol. 50, supplement s7, pp. 55-58, 2009.

[62] S. Gallagher, S. Weiss, J. Oram Cardy, T. Humphries, K. E. Harman, and S. Menascu, "Efficacy of very high dose steroid treatment in a case of Landau-Kleffner syndrome," Developmental Medicine and Child Neurology, vol. 48, no. 9, pp. 766-769, 2006.

[63] W. M. Landau and F. R. Kleffner, "Syndrome of acquired aphasia with convulsive disorder in children," Neurology, vol. 7, no. 8, pp. 523-530, 1957.

[64] W. D. Shields, "Catastrophic epilepsy in childhood," Epilepsia, vol. 41, supplement 2, pp. S2-S6, 2000.

[65] A. Beaumanoir, "The Landau Kleffner syndrome," in Epileptic Syndromes of Infancy, Childhood and Adolescence, A. Beaumanoir, M. Bureau, T. Deonna et al., Eds., pp. 231-244, John Libbey, London, UK, 1991.

[66] R. Nass, L. Heier, and R. Walker, "Landau-Kleffner syndrome: temporal lobe tumor resection results in good outcome," Pediatric Neurology, vol. 9, no. 4, pp. 303-305, 1993.

[67] B. G. R. Neville and S. G. Boyd, "Selective epileptic gait disorder," Journal of Neurology Neurosurgery and Psychiatry, vol. 58, no. 3, pp. 371-373, 1995.

[68] B. G. Neville, V. M. Burch, H. Cass et al., "Behaviioral aspects of Landau-Kleffner syndrome," in Developmental Disability and Behaviour, C. Gillberg and G. O'Brien, Eds., pp. 56-63, Cambridge University Press, London, UK, 2000.

[69] B. G. Neville, V. Burch, H. Cass et al., "Motor disorders in Landau-Kleffner syndrome (LKS)," Epilepsia, vol. 39, article 123, supplement 6, 1998.

[70] R. O. Robinson, G. Baird, G. Robinson, and E. Simonoff, "Landau-Kleffner syndrome: course and correlates with outcome," Developmental Medicine and Child Neurology, vol. 43, no. 4, pp. 243-247, 2001.

[71] M. C. Smith and T. J. Hoeppner, "Epileptic encephalopathy of late childhood: Landau-Kleffner syndrome and the syndrome of continuous spikes and waves during slow-wave sleep," 
Journal of Clinical Neurophysiology, vol. 20, no. 6, pp. 462472, 2003.

[72] M. H. C. Duran, C. A. Guimarães, L. L. Medeiros, and M. M. Guerreiro, "Landau-Kleffner syndrome: long-term followup," Brain and Development, vol. 31, no. 1, pp. 58-63, 2009.

[73] C. Y. Tsao, "Current trends in the treatment of infantile spasms," Neuropsychiatric Disease and Treatment, vol. 5, no. 1, pp. 289-299, 2009.

[74] S. Saltik, D. Uluduz, O. Cokar, V. Demirbilek, and A. Dervent, "A clinical and EEG study on idiopathic partial epilepsies with evolution into ESES spectrum disorders," Epilepsia, vol. 46, no. 4, pp. 524-533, 2005.

[75] T. Deonna and E. Roulet, "Autistic spectrum disorder: evaluating a possible contributing or causal role of epilepsy," Epilepsia, vol. 47, supplement s2, pp. 79-82, 2006.

[76] T. Tsuru, M. Mori, M. Mizuguchi, and M. Y. Momoi, "Effects of high-dose intravenous corticosteroid therapy in LandauKleffner syndrome," Pediatric Neurology, vol. 22, no. 2, pp. 145-147, 2000.

[77] O. N. Markand, "Lennox-Gastaut syndrome (childhood epileptic encephalopathy)," Journal of Clinical Neurophysiology, vol. 20, no. 6, pp. 426-441, 2003.

[78] G. Baner, T. Benke, and K. Bohr, "The Lennox-Gastaut syndrome in adulthood," in The Lennox-Gastaunt Syndrome, E. Niedermeyer and R. Degen, Eds., pp. 317-328, Alan R. Liss, New York, NY, USA, 1988.

[79] K. Farrell and W. O. Tatum, "Encephalopathic generalized epilepsy and Lennox-Gastaut syndrome," in The Treatment of Epilepsy, E. Wyllie, A. Gupta, and D. H. Lachhwani, Eds., vol. 27 , pp. 429-440, Lippincott Williams \& Wilkins, 4th edition, 2006.

[80] A. Beaumanoir and W. Blume, "The Lennox-Gastaut syndrome," in Epileptic Syndromes in Infancy, Childhood and Adolescence, J. Roger, M. Bureau, C. Dravet et al., Eds., pp. 113-136, John Libbey, London, UK, 3rd edition, 2002.

[81] A. Arzimanoglou, J. French, W. T. Blume et al., "LennoxGastaut syndrome: a consensus approach on diagnosis, assessment, management, and trial methodology," The Lancet Neurology, vol. 8, no. 1, pp. 82-93, 2009.

[82] T. Abu Saleh and L. Stephen, "Lennox gastaut syndrome, review of the literature and a case report," Head \& Face Medicine, vol. 4, article 9, 2008.

[83] M. Sazgar and B. F. D. Bourgeois, "Aggravation of epilepsy by antiepileptic drugs," Pediatric Neurology, vol. 33, no. 4, pp. 227-234, 2005.

[84] F. J. DiMario and R. R. Clancy, "Paradoxical precipitation of tonic seizures by lorazepam in a child with atypical absence seizures," Pediatric Neurology, vol. 4, no. 4, pp. 249-251, 1988.

[85] N. Delanty and J. French, "Treatment of Lennox-Gastaut syndrome: current recommendations," CNS Drugs, vol. 10, no. 3, pp. 181-188, 1998.

[86] J. M. Pellock, E. Faught, I. E. Leppik, S. Shinnar, and M. L. Zupanc, "Felbamate: consensus of current clinical experience," Epilepsy Research, vol. 71, no. 2-3, pp. 89-101, 2006.

[87] J. A. Donaldson, T. A. Glauser, and L. S. Olberding, "Lamotrigine adjunctive therapy in childhood epileptic encephalopathy (the Lennox Gastaut syndrome)," Epilepsia, vol. 38, no. 1, pp. 68-73, 1997.

[88] S. Al Ajlouni, A. Shorman, and A. S. Daoud, "The efficacy and side effects of topiramate on refractory epilepsy in infants and young children: a multi-center clinical trial," Seizure, vol. 14, no. 7, pp. 459-463, 2005.
[89] T. Glauser, G. Kluger, R. Sachdeo, G. Krauss, C. Perdomo, and S. Arroyo, "Rufinamide for generalized seizures associated with Lennox-Gastaut syndrome," Neurology, vol. 70, no. 21, pp. 1950-1958, 2008.

[90] S. Hakimian, A. Cheng-Hakimian, G. D. Anderson, and J. W. Miller, "Rufinamide: a new anti-epileptic medication," Expert Opinion on Pharmacotherapy, vol. 8, no. 12, pp. 1931-1940, 2007.

[91] R. Nabbout and O. Dulac, "Epileptic syndromes in infancy and childhood," Current Opinion in Neurology, vol. 21, no. 2, pp. 161-166, 2008.

[92] L. Fusco, C. Pachatz, M. Di Capua, and F. Vigevano, "Video/EEG aspects of early-infantile epileptic encephalopathy with suppression-bursts (Ohtahara syndrome)," Brain and Development, vol. 23, no. 7, pp. 708-714, 2001.

[93] U. Kramer, Y. Nevo, M. Y. Neufeld, A. Fatal, Y. Leitner, and S. Harel, "Epidemiology of epilepsy in childhood: a cohort of 440 consecutive patients," Pediatric Neurology, vol. 18, no. 1, pp. 46-50, 1998.

[94] H. Hwang and K. J. Kim, "New antiepileptic drugs in pediatric epilepsy," Brain and Development, vol. 30, no. 9, pp. 549-555, 2008.

[95] J. W. Wheless, "Nonpharmacologic treatment of the catastrophic epilepsies of childhood," Epilepsia, vol. 45, supplement s5, pp. 17-22, 2004.

[96] P. Parisi, R. Bombardieri, and P. Curatolo, "Current role of vigabatrin in infantile spasms," European Journal of Paediatric Neurology, vol. 11, no. 6, pp. 331-336, 2007.

[97] S. Ohtahara and Y. Yamatogi, "Epileptic encephalopathies in early infancy with suppression-burst," Journal of Clinical Neurophysiology, vol. 20, no. 6, pp. 398-407, 2003.

[98] S. Ohtahara and Y. Yamatogi, "Ohtahara syndrome: with special reference to its developmental aspects for differentiating from early myoclonic encephalopathy," Epilepsy Research, vol. 70, pp. S58-S67, 2006.

[99] J. Aicardi and S. Ohtahara, "Severe neonatal epilepsies with suppression-burst pattern," in Epileptic Syndromes in Infancy, Childhood and Adolescencce, J. Roger, M. Bureau, Ch. Dravet, P. Genton, C. Tassinari, and P. Wolf, Eds., pp. 33-44, John Libbey, Eastleigh, UK, 3rd edition, 2002.

[100] S. Ohtahara, Y. Ohtsuka, Y. Yamatogi, and E. Oka, "The earlyinfantile epileptic encephalopathy with suppression-burst: developmental aspects," Brain and Development, vol. 9, no. 4, pp. 371-376, 1987.

[101] Y. Ohtsuka, M. Sato, S. Sanada, H. Yoshinaga, and E. Oka, "Suppression-burst patterns in intractable epilepsy with focal cortical dysplasia," Brain and Development, vol. 22, no. 2, pp. 135-138, 2000.

[102] A. N. Williams, R. G. Gray, K. Poulton, P. Ramani, and W. P. A. Whitehouse, "A case of Ohtahara syndrome with cytochrome oxidase deficiency," Developmental Medicine and Child Neurology, vol. 40, no. 8, pp. 568-570, 1998.

[103] M. Kato, S. Saitoh, A. Kamei et al., "A longer polyalanine expansion mutation in the ARX gene causes early infantile epileptic encephalopathy with suppression-burst pattern (Ohtahara syndrome)," American Journal of Human Genetics, vol. 81, no. 2, pp. 361-366, 2007.

[104] H. Saitsu, M. Kato, T. Mizuguchi et al., "De novo mutations in the gene encoding STXBP1 (MUNC18-1) cause early infantile epileptic encephalopathy," Nature Genetics, vol. 40, no. 6, pp. 782-788, 2008.

[105] J. González de Dios, M. Moya, C. Pastore, V. Izura, and F. Carratalà, "Early infantile epileptic encephalopathy and 
glycine encephalopathy," Revista de Neurologia, vol. 25, no. 148, pp. 1916-1918, 1997.

[106] H. Yoshikawa, "Early infantile epileptic encephalopathy with suppression burst," No to Hattatsu, vol. 30, no. 6, pp. 551554, 1998.

[107] M. Ishii, K. Tamai, K. Sugita, and Y. Tanabe, "Effectiveness of TRH analog in a case of early infantile epileptic encephalopathy," No to Hattatsu, vol. 22, no. 5, pp. 507-511, 1990.

[108] G. Coppola, A. Verrotti, E. Ammendola et al., "Ketogenic diet for the treatment of catastrophic epileptic encephalopathies in childhood," European Journal of Paediatric Neurology, vol. 14, no. 3, pp. 229-234, 2010.

[109] Y. Takusa, M. Ito, A. Kobayashi, H. Sejima, K. Kishi, and H. Shiraishi, "Effect of the ketogenic diet for West syndrome into which early infantile epileptic encephalopathy with suppression-burst was evolved," No to Hattatsu, vol. 27, no. 5, pp. 383-387, 1995.

[110] J. A. Conry, "Pharmacologic treatment of the catastrophic epilepsies," Epilepsia, vol. 45, supplement s5, pp. 12-16, 2004.

[111] G. Hmaimess, C. Raftopoulos, H. Kadhim et al., "Impact of early hemispherotomy in a case of Ohtahara syndrome with left parieto-occipital megalencephaly," Seizure, vol. 14, no. 6, pp. 439-442, 2005.

[112] H. Komaki, K. Sugai, T. Maehara, and H. Shimizu, "Surgical treatment of early-infantile epileptic encephalopathy with suppression-bursts associated with focal cortical dysplasia," Brain and Development, vol. 23, no. 7, pp. 727-731, 2001.

[113] G. Karvelas, A. Lortie, M. H. Scantlebury, P. T. Duy, P. Cossette, and L. Carmant, "A retrospective study on aetiology based outcome of infantile spasms," Seizure, vol. 18, no. 3, pp. 197-201, 2009.

[114] R. A. Hrachovy and J. D. Frost, "Infantile epileptic encephalopathy with hypsarrhythmia (infantile spasms/west syndrome)," Journal of Clinical Neurophysiology, vol. 20, no. 6, pp. 408-425, 2003.

[115] E. Hancock, J. P. Osborne, and P. Milner, "The treatment of West syndrome: a Cochrane review of the literature to December 2000," Brain and Development, vol. 23, no. 7, pp. 624-634, 2001.

[116] M. T. Mackay, S. K. Weiss, T. Adams-Webber et al., "Practice parameter: medical treatment of infantile spasms: report of the American Academy of Neurology and the Child Neurology Society," Neurology, vol. 62, no. 10, pp. 16681681, 2004.

[117] E. C. Hancock, J. P. Osborne, and S. W. Edwards, "Treatment of infantile spasms," Cochrane Database of Systematic Reviews, no. 4, Article ID CD001770, 2008.

[118] B. Koo, P. A. Hwang, and W. J. Logan, "Infantile spasms: outcome and prognostic factors of cryptogenic and symptomatic groups," Neurology, vol. 43, no. 11, pp. 2322-2327, 1993.

[119] H. Gümüş, S. Kumandaş, and H. Per, "Levetiracetam monotherapy in newly diagnosed cryptogenic west syndrome," Pediatric Neurology, vol. 37, no. 5, pp. 350-353, 2007.

[120] Y. Suzuki, "Zonisamide in West syndrome," Brain and Development, vol. 23, no. 7, pp. 658-661, 2001.

[121] S. Cohen-Sadana, U. Kramera, B. Ben-Zeevb et al., "Multicenter long-term follow-up of children with idiopathic West syndrome: ACTH versus vigabatrin," European Journal of Neurology, vol. 16, pp. 482-487, 2009.

[122] N. Fejerman, R. Cersósimo, R. Caraballo et al., "Vigabatrin as a first-choice drug in the treatment of West syndrome," Journal of Child Neurology, vol. 15, no. 3, pp. 161-165, 2000.
[123] M. A. Mikati, G. A. Lepejian, and G. L. Holmes, "Medical treatment of patients with infantile spasms," Clinical Neuropharmacology, vol. 25, no. 2, pp. 61-70, 2002.

[124] L. J. Willmore, M. B. Abelson, E. Ben-Menachem, J. M. Pellock, and W. Donald Shields, "Vigabatrin: 2008 update," Epilepsia, vol. 50, no. 2, pp. 163-173, 2009.

[125] R. D. Elterman, W. D. Shields, K. A. Mansfield, and J. Nakagawa, "Randomized trial of vigabatrin in patients with infantile spasms," Neurology, vol. 57, no. 8, pp. 1416-1421, 2001.

[126] N. Matar, W. Jin, H. Wrubel, J. Hescheler, T. Schneider, and M. Weiergräber, "Zonisamide block of cloned human T-type voltage-gated calcium channels," Epilepsy Research, vol. 83, no. 2-3, pp. 224-234, 2009.

[127] B. Echenne, O. Dulac, M. J. Parayre-Chanez et al., "Treatment of infantile spasms with intravenous Gamma-Globulins," Brain and Development, vol. 13, no. 5, pp. 313-319, 1991.

[128] G. J. Basura, S. P. Hagland, A. M. Wiltse, and S. M. Gospe, "Clinical features and the management of pyridoxinedependent and pyridoxine-responsive seizures: review of 63 North American cases submitted to a patient registry," European Journal of Pediatrics, vol. 168, no. 6, pp. 697-704, 2009.

[129] O. C. Snead III and E. J. Donner, "A new generation of anticonvulsants for the treatment of epilepsy in children," Paediatrics and Child Health, vol. 12, no. 9, pp. 741-744, 2007.

[130] M. C. Chamberlain, "Nitrazepam for refractory infantile spasms and the Lennox-Gastaut syndrome," Journal of Child Neurology, vol. 11, no. 1, pp. 31-34, 1996.

[131] R. Nabbout, A. Kozlovski, E. Gennaro et al., "Absence of mutations in major GEFS+ genes in myoclonic astatic epilepsy," Epilepsy Research, vol. 56, no. 2-3, pp. 127-133, 2003.

[132] E. M. S. Sherman, D. J. Slick, M. B. Connolly, and K. L. Eyrl, "ADHD, neurological correlates and health-related quality of life in severe pediatric epilepsy," Epilepsia, vol. 48, no. 6, pp. 1083-1091, 2007.

[133] P. Parisi, O. Bruni, M. Pia Villa et al., "The relationship between sleep and epilepsy: the effect on cognitive functioning in children," Developmental Medicine and Child Neurology, vol. 52, no. 9, pp. 805-810, 2010.

[134] P. Parisi, "News on the horizon is not good: interictal epileptic discharges continue to be unaffected by the therapeutic level of AEDs," Epilepsia, vol. 51, no. 5, pp. 933-934, 2010. 


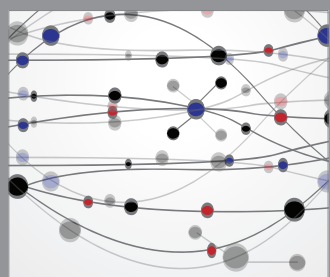

The Scientific World Journal
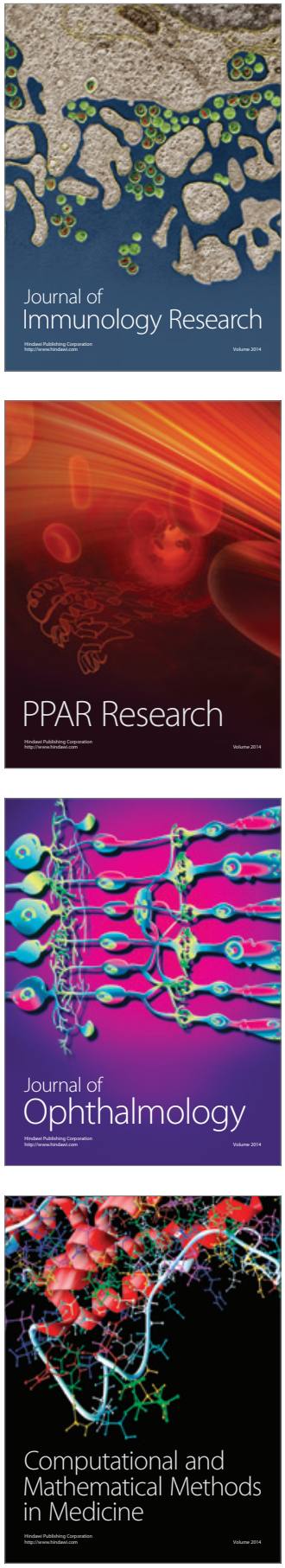

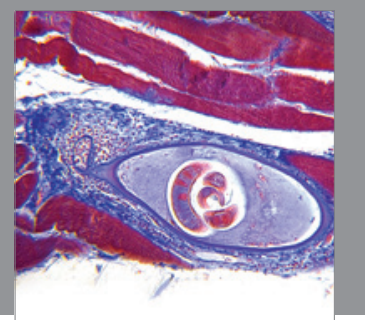

Gastroenterology

Research and Practice
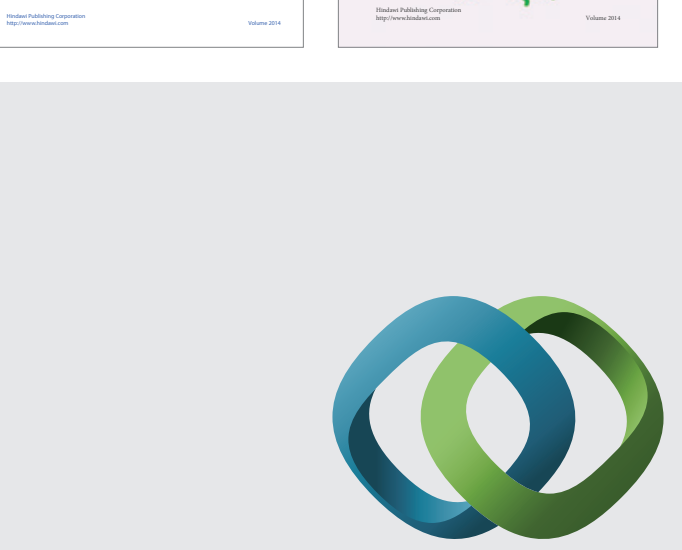

\section{Hindawi}

Submit your manuscripts at

http://www.hindawi.com
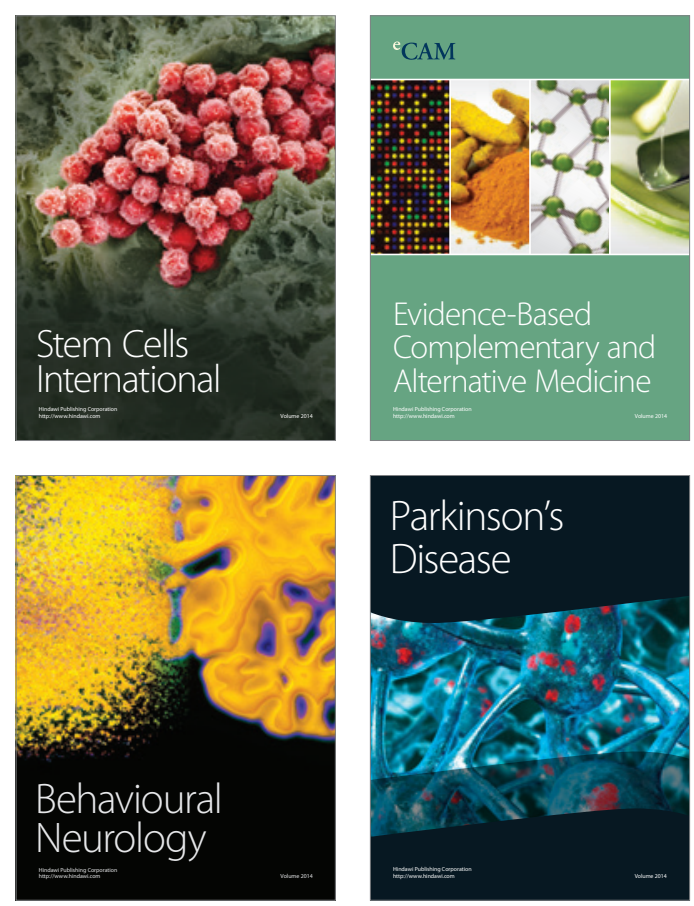

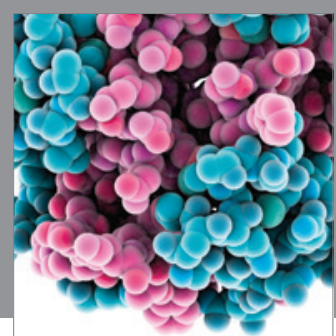

Journal of
Diabetes Research

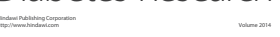

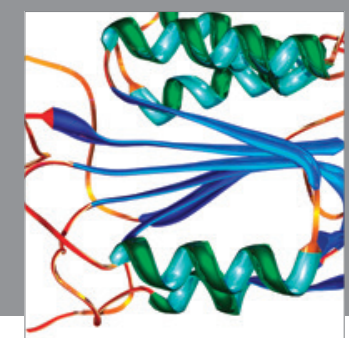

Disease Markers
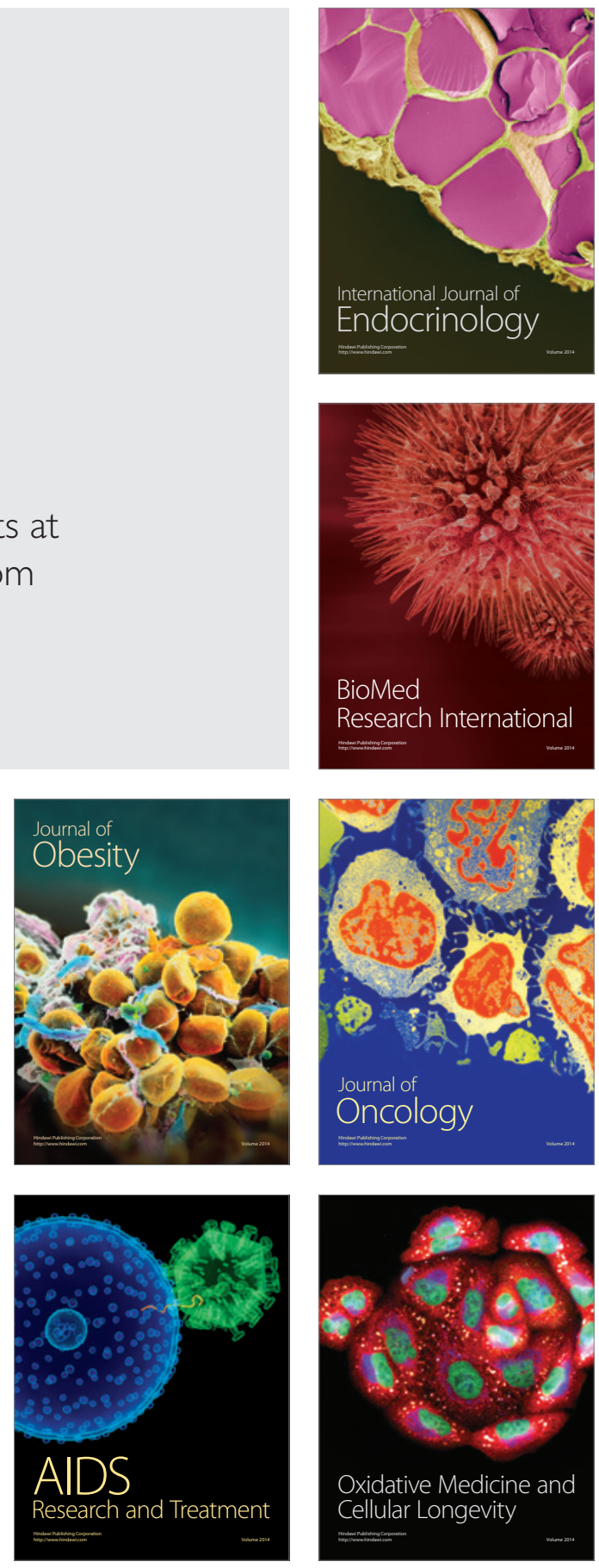